ISSN 2072-6643

www.mdpi.com/journal/nutrients

Article

\title{
Food Intake and Dietary Glycaemic Index in Free-Living Adults with and without Type 2 Diabetes Mellitus
}

\author{
Susan C. McGeoch ${ }^{1}{ }^{*}$, Grietje Holtrop ${ }^{2}$, Claire Fyfe ${ }^{3}$, Gerald E. Lobley ${ }^{3}$, \\ Donald W. M. Pearson ${ }^{1}$, Prakash Abraham ${ }^{1}$, Ian L. Megson ${ }^{4}$, Sandra M. MacRury ${ }^{4}$ \\ and Alexandra M. Johnstone ${ }^{3}$
}

1 Department of Diabetes, Aberdeen Royal Infirmary, Aberdeen AB25 2ZN, UK;

E-Mails: donald.pearson@nhs.net (D.W.M.P.); p.abraham@nhs.net (P.A.)

2 Biomathematics and Statistics Scotland, Edinburgh EH9 3JZ, UK; E-Mail: g.holtrop@abdn.ac.uk

3 The Rowett Institute of Nutrition and Health, University of Aberdeen, Aberdeen AB21 9SB, UK;

E-Mails: c.fyfe@abdn.ac.uk (C.F.); g.lobley@abdn.ac.uk (G.E.L.); alex.johnstone@abdn.ac.uk (A.M.J.)

4 Department of Diabetes \& Cardiovascular Science, University of Highlands and Islands, Inverness IV2 3JH, UK; E-Mails: ian.megson@uhi.ac.uk (I.L.M.); sandra.macrury@uhi.ac.uk (S.M.M.)

* Author to whom correspondence should be addressed; E-Mail: susan.mcgeoch@nhs.net; Tel.: +44-1224-554437; Fax: +44-1224-551186.

Received: 5 May 2011; in revised form: 24 May 2011 / Accepted: 3 June 2011 /

Published: 9 June 2011

\begin{abstract}
A recent Cochrane review concluded that low glycaemic index (GI) diets are beneficial in glycaemic control for patients with type 2 diabetes mellitus (T2DM). There are limited UK data regarding the dietary GI in free-living adults with and without T2DM. We measured the energy and macronutrient intake and the dietary GI in a group $(n=19)$ of individuals with diet controlled T2DM and a group $(n=19)$ without diabetes, matched for age, BMI and gender. Subjects completed a three-day weighed dietary record. Patients with T2DM consumed more daily portions of wholegrains $(2.3 \mathrm{vs} .1 .1, P=0.003)$, more dietary fibre (32.1 vs. $20.9 \mathrm{~g}, P<0.001)$ and had a lower diet GI (53.5 vs. 57.7, $P=0.009)$ than subjects without T2DM. Both groups had elevated fat and salt intake and low fruit and vegetable intake, relative to current UK recommendations. Conclusions: Patients with T2DM may already consume a lower GI diet than the general population but further efforts are needed to reduce dietary GI and achieve other nutrient targets.
\end{abstract}


Keywords: type 2 diabetes mellitus; diet; glycaemic index; lifestyle; food intake

\section{Introduction}

In the UK, lifestyle intervention is the first line of management in type 2 diabetes mellitus (T2DM) [1]. Both the NICE [1] and ADA [2] guidelines recommend that a dietary plan for patients with T2DM should follow the principles of healthy eating. This includes carbohydrate from fruits, vegetables, wholegrains, and pulses (thus a high fibre and lower glycaemic index (GI) diet), reduction in salt intake, the inclusion of low-fat milk and oily fish, and reduced saturated and trans fatty acid intake (e.g., as described by the Food Standards Agency [3], for healthy subjects and by Diabetes UK [4], for patients with type 2 diabetes). This dietary approach is supported by a recent Cochrane review [5] based on meta-analysis of dietary intervention studies. It concluded that low GI diets were beneficial in T2DM and could lead to improvement in glycaemic control with a $0.5 \%$ reduction in $\mathrm{HbA1c}$, used as a marker of glucose excursion. Improved glycaemic control through diet can minimise medication, lessen risk of diabetic complications, improve quality of life and increase life expectancy [5]. Nonetheless, there are limited data available on the dietary GI in free-living patients with and without T2DM. Therefore it is unknown if the GI diets in patients differ from those habitually adopted by individuals with no disease or, indeed, if patients' diets meet current healthy eating advice and nutritional guidelines. The dietary GI of free-living patients with diet-managed T2DM was assessed by Barclay et al. [6], using a food frequency questionnaire (FFQ) in Australians with and without T2DM. They report a similar average GI of 55 in the patients and 57 for those without T2DM. The use of a FFQ is questionable however, because of errors associated with reliance on volunteer memory and variation in individual interpretation of food portion size and frequency. There are no comparable data from a UK cohort of free-living patients. The "gold standard" of assessing food, energy and nutrient intake is considered to be the weighed dietary record [7]. Furthermore, although there are many dietary intervention studies comparing low- and high-GI intervention diets in adults [8-11], there is no consensus as to reference ranges for defining "low" and "high" GI. The reported intervention studies (that assess impact on glycaemic control) involved a dietary range from 43 to 93 GI units in adults.

In view of the current paucity of information in this area, we sought to determine the dietary macronutrient composition and GI in a group of free-living individuals with diet-managed T2DM and a group of controls matched for age, BMI and gender. In addition, their nutrient intake was compared with current UK dietary recommendations and dietary reference values for healthy eating.

\section{Methods}

\subsection{Subject Characteristics}

All volunteers were recruited for studies undertaken by the Human Nutrition Unit at the Rowett Institute of Nutrition and Health, University of Aberdeen. Nineteen patients with T2DM managed by diet alone were recruited by newspaper advertisement and from General Practice. The diagnosis of T2DM was based on standard WHO criteria [12]. Exclusion criteria included medical co-morbidities 
such as cancer, gastrointestinal disease or mental health issues, based on a medical screening questionnaire. Subjects with no apparent T2DM were recruited in a similar manner and underwent a fasting blood glucose measurement to confirm the absence of diabetes. Volunteers with T2DM had received standard National Health Service dietary advice to follow a healthy eating plan, based on Diabetes UK literature [4]. The North of Scotland Research Ethics Service approved the study. Written informed consent was obtained from all participants.

\subsection{Food Intake Recording}

Volunteers with type 2 diabetes recorded all food and drinks consumed for three consecutive days. Volunteers without diabetes recorded food and drink intake for the same three days of the week. Volunteers were provided with digital electronic scales with a tare facility and a food diary for recording food and drinks consumed, time of consumption, weight of food and drink, cooking method and any leftovers. They were instructed to record all recipes and to keep packaging for ready-to-eat food products.

\subsection{Analysis of Food Intake Data}

Diets were analysed using WinDiets Nutritional Analysis Software Suite (Version 1.0, The Robert Gordon University, Aberdeen, UK), a computerized version of McCance and Widdowson: The Composition of Foods 6th Edition [13]. Standard portion sizes were used to input foods with household measures or with missing weights or portion sizes [14]. Total energy and nutrient intake for each meal were quantified. The GI of the different foodstuffs was taken from published reference tables [15]. The tables have some information on ready meals (e.g., pizza, sushi). When this information was not available, the constituent ingredients were entered individually (e.g., spaghetti \& tomato sauce for spaghetti bolognase).

- Dietary GI was calculated as: The sum of the GI value of each foodstuff multiplied by available carbohydrate content (total carbohydrate minus dietary fibre) expressed as a proportion of the total available carbohydrate for the day;

- Dietary glycaemic load (GL) was calculated as: The sum of the product of the GI for each foodstuff and its available carbohydrate content, divided by 100 .

The number of serving of fruit and vegetables was determined as per the British Nutrition Foundation guidelines [16] and number of servings of wholegrain foods was estimated using the US Department of Health guidelines [17].

\subsection{Estimation of Basal Metabolic Rate (BMR)}

BMR for all the volunteers was calculated as described by Schofield et al. [18]. The energy intake (EI)/BMR ratio for each subject was then calculated.

\subsection{Comparison with a Three Day Diet Based on Dietary Recommendations for Type 2 Diabetes}

Based on the menu planner facility on the Diabetes UK [19], a menu was selected for a male aged 60 years, weight of $93 \mathrm{~kg}$, with light activity for weight maintenance, based on our mean volunteer 
characteristics. The three-day menu selected was analysed using WinDiets Nutritional Analysis Software Suite. Total energy and nutrient content for each meal were quantified and the GI, GL and number of portions of fruit and vegetables and whole-grains were determined as above. Means of the values for the three days were then used for comparative purposes. A sample intake for one day included:

Breakfast: $44 \mathrm{~g}$ wholegrain breakfast cereal, $200 \mathrm{~g}$ semi skimmed milk, $150 \mathrm{~g}$ unsweetened fruit juice;

Lunch: $30 \mathrm{~g}$ Lettuce, $85 \mathrm{~g}$ tomato, $15 \mathrm{~g}$ reduced calorie mayonnaise, $175 \mathrm{~g}$ cooked chicken breast, $125 \mathrm{~g}$ low fat fruit yoghurt, $140 \mathrm{~g}$ wholemeal bread;

Dinner: $175 \mathrm{~g}$ cooked extra lean minced beef, $150 \mathrm{~g}$ boiled white rice, $200 \mathrm{~g}$ cauliflower, $170 \mathrm{~g}$ fresh pears, $60 \mathrm{~g}$ vanilla ice-cream;

Snacks: $200 \mathrm{~g}$ semi skimmed milk, $34 \mathrm{~g}$ cereal bar, $100 \mathrm{~g}$ red apples, $25 \mathrm{~g}$ raisins.

\subsection{Statistical Analysis}

For statistical analysis, volunteers with diabetes were paired with 19 volunteers without diabetes on the basis of age, sex, BMI and EI/BMR ratio. Only days where the food diary record was complete were used. For each pairing, food diary data for the same three days of the week were used. Data were analyzed by paired $t$-test. Residual plots were inspected for normality and constant variance. If these assumptions were violated a nonparametric test (Wilcoxon matched pairs test) was used instead. This was necessary for alcohol, fibre intake and portions of fruit, vegetables and whole-grains. Data were analysed using GenStat for Windows (11th Edition); VSN International, Hemel Hempstead, UK.

\section{Results}

\subsection{Comparison of Groups with and without Type 2 Diabetes}

Volunteer characteristics are shown in Table 1.

Table 1. Volunteer characteristics Mean (SD).

\begin{tabular}{|c|c|c|c|}
\hline & $\begin{array}{l}\text { Volunteers without diabetes } \\
\qquad n=19\end{array}$ & $\begin{array}{l}\text { Volunteers with type } 2 \text { diabetes } \\
\qquad n=19\end{array}$ & $p$ \\
\hline Age (years) & $57.8(6.5)$ & $60.1(7.2)$ & 0.41 \\
\hline Male:Female & $15: 4$ & $15: 4$ & - \\
\hline BMI $\left(\mathrm{kg} / \mathrm{m}^{2}\right)$ & $32.1(6.4)$ & $32.5(5.4)$ & 0.86 \\
\hline BMR (kJ/day) & $7713(1289)$ & $7625(1186)$ & 0.67 \\
\hline Energy intake/BMR ratio $(\mathrm{kJ})$ & $1.21(0.24)$ & $1.26(0.43)$ & 0.67 \\
\hline HbA1c (\%) & - & 6.9 (Range: $5.8-8.9$ ) & - \\
\hline
\end{tabular}

There were no significant differences for age, BMI, BMR and male:female ratio between the two groups. The mean BMI of both groups falls within the obese range. The mean EI/BMR was also similar at 1.21 for volunteers without T2DM and 1.26 for volunteers with T2DM. Both values are below the cut-off described by Goldberg et al. [20] who reported that levels of EI below $1.35 \times$ BMR are incompatible with long term maintenance of energy balance and suggests that both groups had a similar tendency to under-report food intake or may simply reflect a modern day sedentary lifestyle.

Table 2 shows total energy, macronutrient intake and dietary GI and GL for the two groups. 
Table 2. Daily total energy, macronutrient intake and dietary GI and GL for both groups.

\begin{tabular}{|c|c|c|c|c|}
\hline & $\begin{array}{l}\text { Volunteers } \\
\text { without diabetes }(n=19)\end{array}$ & $\begin{array}{c}\text { Volunteers with type } 2 \\
\text { diabetes }(n=19)\end{array}$ & $\begin{array}{c}\text { Devised DUK } \\
\text { diet for type } 2 \\
\text { diabetes }\end{array}$ & $\begin{array}{c}P \text { (comparison between } \\
\text { volunteers with and } \\
\text { without diabetes) }\end{array}$ \\
\hline Energy (kJ) & 9289.9 (2331.4) 6087-15147 & 9527.9 (3350.4) 3936-15478 & 9427.4 & 0.79 \\
\hline Energy (kcal) & 2222.5 (557.8) 1456-3624 & 2270.5 (812.2) 942-3703 & 2255.4 & 0.82 \\
\hline Fat \% of energy & $32.1(8.1) 15-43$ & $33.5(8.3) 22-54$ & $26.8 *$ & 0.59 \\
\hline Protein \% of energy & $17.2(3.9) 11-26$ & $20.3(3.5) 14-29$ & $27.9^{\$}$ & 0.034 \\
\hline CHO \% of energy & $46.0(9.2) 32-64$ & 47.2 (10.4) 28-68 & 45.4 & 0.72 \\
\hline Saturated fat $\%$ of energy & 11.7 (4.2) 3.7-18.9 & 10.8 (4.3) $0.7-21$ & $8.6 *$ & 0.51 \\
\hline Salt (g) & $8.2(2.9) 2.6-14.5$ & 8.8 (3.6) 3.2-15.9 & $5^{\$}$ & 0.57 \\
\hline Alcohol (kJ) & $571.3(767.2) 0-2551$ & $0.14(0.6) 0-2.65$ & 0 & $<0.001$ \\
\hline Saturated fat (g) & 30.0 (19.9) 7.5-77.5 & $31.4(19.9) 1.1-87.5$ & 21.9 & 0.81 \\
\hline Total sugars (g) & 96.2 (50.3) 24.7-235 & $99.2(36.2) 47-179$ & $130.2 *$ & 0.84 \\
\hline Dietary fibre (g) & 20.9 (4.4) $10.7-20.9$ & 32.1 (15.6) 11.0-76.9 & 29.2 & $<0.001$ \\
\hline $\begin{array}{l}\text { Portions of fruit and } \\
\text { vegetables }\end{array}$ & $3.81(2.5) 0-8.7$ & 3.94 (1.7) $2.0-8.3$ & $6.3^{\$}$ & 0.93 \\
\hline $\begin{array}{l}\text { Portions of wholegrain } \\
\text { foodstuffs }\end{array}$ & $1.1(0.84) 0-3.0$ & $2.3(1.5) 0-6.0$ & 2 & 0.003 \\
\hline Available CHO (g) & $241.3(62.5) 152-361$ & 242.8 (83.9) $108-403$ & 237.6 & 0.95 \\
\hline Dietary GI & $57.7(4.8) 47-65$ & $53.5(3.9) 47-61$ & 54.4 & 0.009 \\
\hline Dietary GL & $139.9(40.2) 81-223$ & 130.6 (48.0) 59-220 & 129.3 & 0.49 \\
\hline
\end{tabular}

Mean (SD) Range; Comparison between the diets of volunteers with T2DM and Diabetes UK menu: * $P<0.05,{ }^{\$} P<0.001$;

GI: Glycameic Index, GL: Glycaemic Load.

Total EI and percentage of energy derived from either fat or carbohydrate were similar for the two groups, with patients with T2DM consuming a higher percentage of energy from protein (20.3 vs. 17.2\%, $P=0.034)$. The group with T2DM also ate more dietary fibre $(32.1 v s .20 .9 \mathrm{~g}$, $P<0.001)$ explained in part by consumption of more portions of whole-grains $(2.3 \mathrm{vs.} 1.1, P=0.003)$. These differences contributed to the lower dietary GI $(53.5$ vs. $57.7, P=0.009)$ for this group, although the dietary GL was similar $(P=0.49)$, as were the sugar $(P=0.84)$ and available carbohydrate $(P=0.95)$ intakes.

\subsection{Comparison of Group Data with Reference Values}

Table 2 also details the results for total energy intake, macronutrient composition, GI and GL calculated from the Diabetes UK (DUK) meal plan for patients with T2DM. If this planner is considered a guidance level, then several of the nutrient intakes were met, including dietary GI, GL, fibre intake and portions of whole-grains. In contrast, intake of salt was above the $5 \mathrm{~g} / \mathrm{day}$ recommendation (at $8.8 \mathrm{~g} /$ day), while daily fruit and vegetable consumption (average 3.9 portions) was well below the 6.3 level from the DUK meal plan. Saturated fat intake was also much higher at $31.4 \%$ in comparison to the healthier $21.9 \%$ in the planner; total fat intake at $33.5 \%$ was also higher than the DUK meal plan (26.8\%). The percentage of total energy derived from protein, however, was less than the DUK meal plan (20.3 vs. $27.9 \%)$. 
Notably, both patients with T2DM and subjects without disease had similar levels in total fat and saturated fat intake, expressed as a percentage of total energy intake (Table 2). However, these levels would only be considered acceptable for a non-diseased population, as they are only slightly higher than that recommended for the general population (healthy, non diabetic) for optimal health (DOH [21]: 30\% fat and 10\% saturated fat from energy). Both groups had low fruit and vegetable intake, much less than the 5-6 portions a day recommended for the UK population while salt intake was higher than that recommended for the general population ( $6 \mathrm{~g} / \mathrm{day}$ [3]). Thus, these trends are not specific to the patient group with T2DM, but reflect more the general problems associated with the typical "Scottish Diet".

\section{Discussion}

To our knowledge this is the first study to evaluate the dietary GI for a group of free-living diet-managed individuals with T2DM in the UK. This study therefore provides an estimation of habitual intake that provides a reference for dietary intervention studies performed under controlled laboratory conditions (with test meals and novel products).

\subsection{Dietary Glycaemic Index (GI)}

The present study indicated that patients with T2DM consumed a relatively healthy diet, with more portions of whole-grains, dietary fibre and a slightly lower dietary GI than a matched group of obese individuals with no T2DM. These findings probably reflect the dietary advice received at diagnosis. Indeed, the meal plan from DUK had a similar GI of 54. These findings are also comparable with those of Barclay et al. [6], using the FFQ tool, who reported a dietary GI of 55 and 57 for subjects with and without T2DM, respectively. Other cultures report a slightly higher dietary GI in healthy subjects, e.g., one study of Japanese women involved a mean GI of 64 [22].

There are numerous intervention studies comparing high and low GI diets in the management of T2DM and these are summarised in Table 3 [8-10,23-28].

Table 3. The glycaemic index of the diets used in studies that showed an improvement in glycaemic control with a low GI diet.

\begin{tabular}{|l|c|c|c|}
\hline Study & High GI diet mean GI & Low GI diet mean GI & Difference in GI \\
\hline Wolever et al. $[24]$ & 87 & 60 & 27 \\
\hline Jenkins et al. $[23]$ & 90.5 & 67.3 & 23.2 \\
\hline Frost et al. $[10]$ & 82 & 77 & 5 \\
\hline Fontvieille et al. $[9]$ & 64 & 38 & 26 \\
\hline Jarvi et al. $[25]$ & 82.7 & 56 & 26.7 \\
\hline Jenkins et al. $[26]$ & 86 & 62 & 24 \\
\hline Rizkalla et al. $[27]$ & 71 & 39 & 32 \\
\hline Jimenez-Cruz et al. $[28]$ & 56 & 44 & 12 \\
\hline Brand et al. $[8]$ & 91 & 77 & 14 \\
\hline Mean & $\mathbf{7 8 . 9}$ & $\mathbf{5 7 . 8}$ & $\mathbf{2 1 . 1}$ \\
\hline
\end{tabular}


The arithmetic mean of the low GI diets was 58 (range 38-77) while the mean of high GI diets was 79 (range 56-91). Compared with these intervention studies, our current volunteers are therefore already eating a diet within the "low" GI range. Within the confines of normal "healthy" eating, the options to reduce the dietary GI much further are probably limited and, therefore, additional dietary advice to lower the dietary GI may not lead to further improvements in glycaemic control. Interestingly, the volunteers without T2DM had only slightly higher dietary GI, although other aspects of their diet were less healthy. The usefulness of the concept of GI has been questioned in relation to healthy eating advice, in particular for subjects without diabetes as it is subject to technical [29], practical [30] and theoretical limitations [31]. Furthermore, people do not usually eat single foods and combining carbohydrate products with other macronutrients can affect the overall estimation of meal GI [29]. Nonetheless, the concept of GI is relatively easily understood by patients, and although flawed, is probably the most sensible approach currently available.

\subsection{Total Energy Intake}

Mean EI was similar for both the groups, as was the average EI/BMR ratio. Similar values have been reported in other patient studies [6,32] and healthy subjects [33]. It is recognised that dietary assessment methods have a strong bias towards underestimation of habitual energy intake [34], but weighed diet records are considered the "gold standard" when examining free-living energy and nutrient intake [7].

\subsection{Diet Composition}

The group with T2DM consumed similar proportions of total energy as carbohydrate and fat but with a higher fraction from protein compared with the non-patient group. These proportions of intake are also comparable with other work based on food diary data $[6,35,36]$. Fibre intake in both groups exceeds current UK guidelines for the general population (18 g/day) [21] and is higher than the average fibre intake in the general Scottish population (12 g/day, [37]), suggesting that both groups were more nutritionally aware than the general public. Both groups, however, consumed in excess of the recommended daily salt intake. In view of the increased cardiovascular risk associated with diabetes [38] and the link between salt intake and hypertension [39] this is identified as an area where further education may improve diet and health profiles.

\subsection{Comparison with the DUK Menu Plan}

In comparison with the menu plan from DUK, patients met the targets for GI, GL, dietary fibre and whole-grains. The number of portions of fruit and vegetable intake was low, but similar to that reported for the general Scottish population (3.2 for women and 3.0 for men [40]). The protein content of the DUK menu (1.7 $\mathrm{g} / \mathrm{kg}$ body weight) is higher than that usually recommended for those with diabetes where $1 \mathrm{~g} / \mathrm{kg}$ body weight should not be exceeded [41]. 


\subsection{Implications for Clinical Practice}

It is reassuring that volunteers were able to achieve dietary GI comparable with those used in dietary intervention studies that have resulted in an improved glycaemic control. This reinforces the benefits of dietary intervention as the first line management in type 2 diabetes. Whether even lower GI diets might be more beneficial cannot be ascertained from the current study, but there may be practical limitations for a habitual lifestyle. If the current results are typical of individuals with Type 2 diabetes stabilised by life-style advice, then current dietary advice seems to be effective in improving both fibre and whole grain consumption. Nonetheless, the data suggest that more education needs to be focused on reduction of salt and saturated fat intake plus a drive to further increase fruit and vegetable consumption.

It is also unclear whether low GI diets are the best dietary strategy for optimising glycaemic control in T2DM. Reduction in percentage of energy of the diet derived from carbohydrate will result in a lower dietary GL and it could be postulated that this might lead to improved glycaemic control. However, studies to date have not demonstrated convincing benefits of reduced carbohydrate diets on glycaemic control when compared with low GI diets or standard healthy eating. For example, Daly et al. [42] randomised volunteers to receive either education regarding standard healthy eating or a low carbohydrate diet and found that although participants who followed the low carbohydrate diet lost more weight and had improved lipid profiles there were no differences in glycaemic control between the two groups. Further research needs to be undertaken, therefore, to determine the best dietary strategies to optimise glycaemic control in individuals with T2DM.

\subsection{Study Limitations}

The subject numbers are relatively small and it is recognised that dietary assessment methods can be inaccurate and are biased towards patient under-reporting [7]. The determination of dietary GI and GL are from published reference tables that are often incomplete and may lead to under or over-estimation of meal values. These patient volunteers also had been effective in regulating their diabetes by lifestyle changes alone and therefore may not be typical of the attitude and/or determination of those newly diagnosed with the disease. As a cohort, they do illustrate the potential effectiveness of this type of disease management.

\section{Conclusions}

Patients with diet-managed type 2 diabetes mellitus may already consume a low-GI diet, but may not be meeting other nutrient targets, and dietary advice should also focus on reducing salt intake and increasing fruit and vegetable intake.

\section{Acknowledgements}

Funding for this study has been provided by The Chief Scientist Office of Scotland; Research and Development Endowments at NHS Highland; University of Aberdeen Rowett Institute of Nutrition and Health. 
We would like to thank all the volunteers who participated in this study as well as Sylvia Stephen, Jean Bryce, Nina Lanza and Karen Taylor for assistance in the Human Nutrition Unit at the Rowett Institute of Nutrition and Health.

\section{Conflict of Interest}

The authors declare no conflict of interest.

\section{References}

1. National Collaborating Centre for Chronic Conditions. Type 2 Diabetes: National Clinical Guideline for Management in Primary and Secondary Care (Update); Royal College of Physicians: London, UK, 2008.

2. American Diabetes Association. Nutritional Recommendations and Interventions for Diabetes. Diabetes Care 2007, 30, 548-565.

3. Food Standards Agency. Available online: http://www.eatwell.gov.uk/healthydiet/eatwellplate (accessed on 1 November 2010).

4. Diabetes UK. Available online: http://www.diabetes.org.uk/Guide-to-diabetes/Healthy_lifestyle/ Eating_Well/ (accessed on 1 November 2010).

5. Thomas, D.; Elliott, E.J. Low glycaemic index, or low glycaemic load, diets for diabetes mellitus. Cochrane Database Syst. Rev. 2009, 1, CD006296, doi:10.1002/14651858. CD006296.pub2.

6. Barclay, A.W.; Brand-Miller, J.C.; Mitchell, P. Macronutrient intake, glycaemic index and glycaemic load of older Australian subjects with and without diabetes: Baseline data from the Blue Mountains Eye Study. Br. J. Nutr. 2006, 96, 117-123.

7. Bingham, S.A. The dietary assessment of individuals; methods accuracy, new techniques and recommendations. Nutr. Abstr. Rev. 1987, 57, 705-742.

8. Brand, J.C.; Colagiuri, S.; Crossman, S.; Allen, A.; Roberts, D.C.; Truswell, A.S. Low glycaemic index foods improve long term glycaemic control in NIDDM. Diabetes Care 1991, 14, 95-101.

9. Fontvieille, A.M.; Rizhalla, S.W.; Penfornis, A.; Acosta, M.; Bornet, F.R.; Slama, G. The use of low glycaemic index foods improves metabolic control of diabetic patients over five weeks. Diabet. Med. 1992, 9, 444-450.

10. Frost, G.; Wilding, J.; Beecham, J. Dietary advice based on the glycaemic index improves dietary profile and metabolic control in type 2 diabetic patients. Diabet. Med. 1994, 11, 397-401.

11. Giacco, R.; Parillo, M.; Rivellese, A.; Lasorella, G.; Giacco, A.; D’Episcopo, L.; Riccardi, G. Long-term dietary treatment with increased amounts of fiber-rich low-glycemic index natural foods improves blood glucose control and reduces the number of hypoglycemic events in type 1 diabetic patients. Diabetes Care 2000, 23, 1461-1466.

12. World Health Organization. Definition and Diagnosis of Diabetes Mellitus and Intermediate Hyperglycemia: Report of a WHO/IDF Consultation; WHO Press, World Health Organization: Geneva, Switzerland, 2006.

13. Food Standards Agency. McCance and Widdowson's the Composition of Foods, 6th ed.; Royal Society of Chemistry: Cambridge, UK, 2002. 
14. Ministry of Agriculture Fisheries and Food. Food Portion Sizes. Food Standards Agency, 3rd ed.; Crawley, H., Ed.; The Stationary Office: London, UK, 1988.

15. Foster-Powell, K.; Holt, S.H.A.; Brand-Miler, J.C. International table of glycemic index and glycemic load values. Am. J. Clin. Nutr. 2002, 76, 5-56.

16. British Nutrition Foundation, Healthy Eating, Fruit and Vegetables. Available online: http://www.nutrition.org.uk (accessed on 1 November 2010).

17. US Department of Health and Human Services and US Department of Agriculture. Dietary Guidelines for Americans, 6th ed.; US Government Printing Office: Washington, DC, USA, 2005.

18. Schofield, W.N. Predicting basal metabolic rate, new standards and review of previous work. Hum. Nutr. Clin. Nutr. 1985, 39, 5-41.

19. Diabetes UK. Menu planner. Available online: http://www.storetour.co.uk/MenuPlanner.aspx (accessed on 1 November 2010).

20. Goldberg, G.R.; Black, A.E.; Jebb, S.A.; Cole, T.J.; Murgatroyd, P.R.; Coward, W.A.; Prentice, A.M. Critical evaluation of energy intake data using fundamental principles of energy physiology: 1. Derivation of cut-off limits to identify under-recording. Eur. J. Clin. Nutr. 1991, 45, 569-581.

21. Department of Health. Dietary Reference Values for Food Energy and Nutrients in the United Kingdom; HMSO: London, UK, 1991.

22. Amano, Y.; Kawakubo, K.; Lee, J.S.; Tang, A.C.; Sugiyama, M.; Mori, K. Correlation between dietary glycaemic index and cardiovascular disease risk factors among Japanese women. Eur. J. Clin. Nutr. 2004, 58, 1472-1478.

23. Jenkins, D.J.; Wolever, T.M.; Buckley, G.; Lam, K.Y.; Giudici, S.; Kalmusky, J.; Jenkins, A.L.; Patten, R.L.; Bird, J.; Wong, G.S.; Josse, R.G. Low-glycaemic index starchy foods in the diabetic diet. Am. J. Clin. Nutr. 1988, 48, 248-254.

24. Wolever, T.M.S.; Jenkins, D.J.; Vuksan, V.; Jenkins, A.L.; Buckley, G.C.; Wong, G.S.; Josse, R.G. Beneficial effect of a low glycaemic index diet in type 2 diabetes. Diabet. Med. 1992, 9, 451-458.

25. Jarvi, A.E.; Karlsrom, B.E.; Granfeldt, Y.E.; Bjorck, I.E.; Asp, N.L.; Vessby, B.O.H. Improved glycaemic control and lipid profile and normalised fibrinolytic activity on a low glycaemic index diet in type 2 diabetic patients. Diabetes Care 1999, 22, 10-18.

26. Jenkins, D.J.A.; Kendall, C.W.C.; McKeown-Eyssen, G.; Josse, R.G.; Silverberg, J.; Booth, G.L.; Vidgen, E.; Josse, A.R.; Nguyen, T.H.; Corrigan, S.; et al. Effect of a low glycaemic index or a high cereal fibre diet on type 2 diabetes. JAMA 2008, 300, 2742-2753.

27. Rizkalla, S.W.; Taghrid, L.; Laromiguiere, M.; Huet, D.; Boillot, J.; Rigoir, A.; Elgrably, F.; Slama, G. Improved plasma glucose control, whole body glucose utilization and lipid profile on a low glycaemic index diet in type 2 diabetic men. Diabetes Care 2004, 27, 1866-1872.

28. Jimenez-Cruz, A.; Bacardi-Gascon, M.; Turnbull, W.H.; Rosales-Garay, P.; Serverino-Lugo, I. A flexible, low-glycaemic index Mexican style diet in overweight and obese subjects with type 2 diabetes improves metabolic parameters during a 6 week treatment period. Diabetes Care 2003, 26, 1967-1970.

29. Pi-Sunyer, F.X. Glycaemic index and disease. Am. J. Clin. Nutr. 2002, 76, 290S-298S. 
30. Brouns, F.; Bjork, I.; Frayn, K.N.; Gibbs, A.L.; Lang, V.; Slama, G.; Wolever, T.M.S. Glycaemic index methodology. Nutr. Res. Rev. 2005, 18, 145-171.

31. Bahado-Singh, P.S.; Wheatley, A.O.; Ahmad, M.H.; Morrison, E.Y.; Asemota, H.N. Food processing methods influence the glycaemic indices of some commonly eaten West Indian carbohydrate-rich foods. Br. J. Nutr. 2006, 96, 476-481.

32. Wolever, T.M.S.; Nguyen, P.M.; Chiasson, J.L.; Hunt, J.A.; Josse, R.G.; Palmason, C.; Rodger, N.W.; Ross, S.; Ryan, E.A.; Tan, M.H. Determinants of diet glycaemic index calculated retrospectively from diet records of 342 individuals with non-insulin dependant diabetes mellitus. Am. J. Clin. Nutr. 1994, 59, 1265-1269.

33. Visockiene, Z.; Broom, I.; Speakman, J.R.; Johnstone, A.M. Dietary intake and self-reporting in relation to eating behaviour in obese and Type 2 diabetes patients. Baltic Endocrinol. 2006, 2, 24-30.

34. Black, A.E.; Goldberg, G.R.; Jebb, S.A.; Livingstone, M.B.; Cole, T.J.; Prentice, A.M. Critical evaluation of energy intake data using fundamental principles of energy physiology: Evaluating the results of published surveys. Eur. J. Clin. Nutr. 1991, 45, 583-599.

35. Eeley, E.A.; Stratton, I.M.; Hadden, D.R.; Turner, R.C.; Holman, R.R. UKPDS 18: Estimated Dietary Intake in Type 2 Diabetic Patients randomly allocated to diet, sulphonylurea or insulin therapy. Diabet. Med. 1996, 13, 656-662.

36. Close, E.J.; Wiles, P.G.; Lockton, J.A.; Walmsley, D.; Oldham, J.; Wales, J.K. Diabetic diets and nutritional recommendations: What happens in real life? Diabet. Med. 1992, 9, 181-188.

37. Expenditure and Food Survey (EFS) 2003/2004. Available online: http://www.food.gov.uk/ multimedia/pdfs/scotdietrytarg.pdf (accessed on 1 November 2010).

38. Haffner, S.M.; Lehto, S.; Rönnemaa, T.; Pyörälä, K.; Laakso, M. Mortality from Coronary Heart Disease in Subjects with Type 2 Diabetes and in Non-diabetic Subjects with and without Prior Myocardial Infarction. N. Engl. J. Med. 1998, 339, 229-234.

39. Dahl, L.K. Salt and hypertension. Am. J. Clin. Nutr. 1972, 25, 231-244.

40. The Scottish Health Survey 2003. Available online: http://www.scotland.gov.uk/Resource/Doc/ 76169/0019729.pdf (accessed on 1 November 2010).

41. Nutrition Subcommittee of the Diabetes Care Advisory Committee of Diabetes UK. The implementation of nutritional advice for people with diabetes. Diabet. Med. 2003, 20, 786-807.

42. Daly, M.E.; Paisey, R.; Millward, B.A.; Eccles, C.; Williams, K.; Hammersley, S.; MacLeod, K.M.; Gale, T.J. Short-term effects of severe dietary carbohydrate restriction advice in Type 2 diabetes — a randomised controlled trial. Diabet. Med. 2006, 23, 15-20.

(C) 2011 by the authors; licensee MDPI, Basel, Switzerland. This article is an open access article distributed under the terms and conditions of the Creative Commons Attribution license (http://creativecommons.org/licenses/by/3.0/). 